When the rather curious geometry of the emergent beam is realized, it will be seen that

$$
\begin{aligned}
& \text { length of first focal line }=\frac{\text { distance between lines }}{\mathrm{OF}_{2}} \\
& \text { length of second focal line }=\frac{\text { distance between lines }}{\mathrm{OF}_{1}}
\end{aligned}
$$

and these lengths, calculated with a slide rule, complete the table.

Focal lines of a Small Cylindrical Beam of Parallel Rays Passing through the Centre of a Symmetrical

\begin{tabular}{|c|c|c|c|c|c|c|c|}
\hline \multirow[b]{2}{*}{1 Inclination of beam to axis of lens } & \multicolumn{7}{|c|}{ All Measurements are in CM. } \\
\hline & $0^{\circ}$ & $5^{\circ *}$ & $10^{\circ}$ & $15^{\circ}$ & $20^{\circ}$ & $25^{\circ}$ & $30^{e}$ \\
\hline $\begin{array}{l}2 \text { Distance of first focal line from } \\
\text { centre of lens }\end{array}$ & 100 & $98.9 ́ 3$ & 95.71 & 90.84 & 84.13 & 76.31 & 67.53 \\
\hline 3 Length of first focal line for an & 0 & $\cdot 009$ & .034 & .070 & .125 & .186 & .260 \\
\hline $\begin{array}{l}4 \text { Distance of second focal line from } \\
\text { centre of lens }\end{array}$ & 100 & 99.8 & 99.1 & 97.7 & 96.1 & 93.7 & 91.2 \\
\hline $\begin{array}{l}5 \text { Length of second focal line for an } \\
\text { incident beam } 1 \mathrm{~cm} \text {. diameter... }\end{array}$ & 0 & .009 & .035 & .076 & .143 & .228 & .352 \\
\hline 6 Shortening of focal length for first & 0 & 1.07 & 4.29 & 9.16 & 15.87 & 23.69 & 32.47 \\
\hline 7 Figures from Bardsley's chart ... & 0 & .70 & 3. & 7. & 12.5 & 21. & 31. \\
\hline $\begin{array}{l}8 \text { By law of squares assuming the } \\
\text { value for } 30 \text { degrees correct }\end{array}$ & 0 & .90 & 3.61 & 8.12 & 14.43 & 22.59 & 32.47 \\
\hline
\end{tabular}

Double Convex Lens of 100 CM. Focal Length.

The figures of the seventh line are from a chart that had been submitted to the writer for criticism, and that gave rise to the investigation.

\title{
A CASE OF POISONING BY HOMATROPIN
}

$$
\text { JaMES A. CRAIG, M.B., F.R.C.S.I., }
$$

LECTURER IN OPHTHALMOLOGY, QUEEN'S UNIVERSITY OF BELFAST.

CASES of poisoning due to the instillation into the eye of solutions of homatropin, are, I think, sufficiently rare to justify the publication of the following case. As will be seen from the statement, there is room for conjecture as to whether the symptoms were entirely due to idiosyncrasy on the part of the patient, or at least in some degree to impurity of the drug. This was the product 
of perhaps the best known and most trustworthy of our British manufacturing chemists, and was dispensed by a local firm with a very high reputation for accuracy.

The patient, A.B., aet. $5 \frac{1}{2}$ years, suffering from hypermetropic astigmatism, had, two years earlier, had her refraction determined after atropinization. On this occasion, a solution of sulphate of atropin, gr. 4 to $\xi 1$, had been dropped into each eye twice daily for three consecutive days. There was then no symptom whatever of belladonna poisoning, so that it may safely be assumed that the patient had no undue susceptibility to atropin.

On her return two years later for re-examination, it was considered sufficient to use homatropin. A drop of the solution, 4 gr. to 31 , was instilled into each eye, and the child was allowed to go out with her mother to visit some friends in the immediate neighbourhood, with instructions to return in an hour. When she did return -two hours later-the cause of the delay was sufficiently obvious. The child was in a condition of intense mental excitement, laughing, talking incoherently, and with hallucinations of vision. She also complained of dryness of the mouth. As examination was out of the question she was sent home. The excitement continued without abatement until 3 o'clock in the following morning (i.e., ten hours), when she fell asleep. On waking five or six hours later, her condition had become normal.

The same solution has been frequently used since. In the majority of cases, the patient has been conscious of no unusual general effects. In one or two, however, there has been produced a slight sensation of giddiness together with some dryness of the mouth. This would suggest that impurity of the drug, may, in some degree, account for the facts of the case.

\title{
A CASE OF CONGESTIVE GLAUCOMA AFTER THE USE OF HOMATROPIN AND ESERIN
}

\author{
BY \\ H. M. Desai, D.Ch.O. (Liverpool), \\ SURGICAL OFFICER IN CHARGE, EYE INFIRMARY, SUNDERLAND.
}

MRS. S. B., aged 48 years, attended the Sunderland Eye Infirmary on May 3, 1918, to have her eyes tested for distant glasses. Had glasses for near work in October, 1917, and they were quite satisfactory. $\mathrm{V} .=6 / 18$. Tension, as tested by the fingers, was normal and pupil reaction was good. Mydriasis was produced by homatropin 1 per cent. and a drop of eserin sulph. 1 per cent. was instilled in each eye before the patient left. Refraction $+4.5 \mathrm{D}$. in 